\title{
Total volatile fatty acid concentrations are unreliable estimators of treatment effects on ruminal fermentation in vivo ${ }^{1}$
}

\author{
M. B. Hall, ${ }^{* 2}$ T. D. Nennich, $†$ P. H. Doane, $\ddagger$ and G. E. Brink* \\ *US Dairy Forage Research Center, USDA-Agricultural Research Service, Madison, WI 53706 \\ †Department of Animal Sciences, Purdue University, West Lafayette, IN 47907 \\ †ADM Research, Decatur, IL 62526
}

\begin{abstract}
Volatile fatty acid concentrations ([VFA], $\mathrm{m} M)$ have long been used to assess the effect of dietary treatments on ruminal fermentation in vivo. However, discrepancies in statistical results between [VFA] and VFA pool size (VFAmol) possibly related to ruminal digesta liquid amount (LIQ, $\mathrm{kg}$ ) indicate potential issues with the use of [VFA]. We investigated relationships among [VFA], VFAmol, and LIQ measured $2 \mathrm{~h}$ postfeeding using individual lactating cow data $(\mathrm{n}=175)$ from 7 separate feeding studies. Regression analyses were performed using mixed models with "study" as a discrete random variable. The mean across studies and average range of values within studies, respectively, were 151 and 75 for [VFA], 11.2 and 9.8 for VFAmol, 73.3 and 41.0 for LIQ, and 289 and $83 \mathrm{mmol} / \mathrm{kg}$ for rumen fluid osmolality. Liquid amount changed with VFAmol (3.76 VFAmol + 31.2 ; average within-study $\mathrm{R}^{2}=0.69$ ), but the relationship was weak between [VFA] and LIQ (0.524 LIQ + 112.8; average within-study $\mathrm{R}^{2}=0.12$ ). The relationship between LIQ and VFAmol was likely a function of the osmotic gradient between rumen liquid and blood. The VFA are a major ruminal solute; VFAmol amounts can affect water flux in the rumen as similar tonicities of rumen fluid and blood are maintained. This also has a damping effect on ruminal solute concentration, creating the weak relationship between [VFA] and LIQ. Within studies, similar [VFA] were found in LIQ differing by $30 \mathrm{~kg}$ or more. The difference between minimum and maximum LIQ within cow within study was 12.7 $\mathrm{kg}$ (standard deviation $=7.1$ ), so inclusion of "cow" in analyses did not correct for the variation in LIQ. To allow valid comparisons of experimental treatments, responses must be on an equivalent basis; concentra-
\end{abstract}

Received September 15, 2014.

Accepted February 13, 2015.

${ }^{1}$ Mention of any trademark or proprietary product in this paper does not constitute a guarantee or warranty of the product by the USDA or the Agricultural Research Service and does not imply its approval to the exclusion of other products that also may be suitable.

${ }^{2}$ Corresponding author: marybeth.hall@ars.usda.gov tions in different LIQ are not on an equivalent basis and so are not valid to use for comparing treatment effects. The [VFA] changed with VFAmol (5.80 VFAmol +86.3 ; average within-study $\mathrm{R}^{2}=0.56$ ). However, the ratio of [VFA] to VFAmol ranged from 9.0 to 24.1 as a function of 1,000/LIQ; this reflects the inherent calculated relationship among the variables. The varying relationship of [VFA] to VFAmol further indicates that [VFA] is not an appropriate measure to evaluate the progress or effect of treatments on ruminal fermentation. Predictions of LIQ and VFAmol using cow and ruminal measures were insufficiently precise to be used in research. Previously drawn conclusions based on [VFA] need to be reevaluated, and alternate evaluations for in vivo ruminal fermentation are needed.

Key words: volatile fatty acid concentration, ruminal fermentation, rumen digesta, regression analysis

\section{INTRODUCTION}

A fundamental principle of comparing experimental treatments is that all data are on an equivalent basis. It is for this reason that packed cell volume may be used as a covariate for evaluation of plasma values, or why dietary composition is evaluated on a dry matter basis, rather than "as fed." In the laboratory, concentrations of analytes detected in diluted samples are only useful if the dilution factor or the weight of sample and final dilution volume are known.

Ruminal concentrations of VFA ([VFA]) and other analytes have been used to describe the progress of ruminal fermentation in vivo (Phillipson, 1942) and the effects of dietary treatments since at least the 1940s. Rumen [VFA] are still commonly used to make statistical inferences regarding the effect of treatments on in vivo ruminal fermentation (e.g., Hall et al., 2010; 37 publications in the Journal of Dairy Science and Journal of Animal Science in 2012, alone). The authors may or may not be specific regarding what effect on fermentation is represented by the change in concentration, but the common implication is that treatments relatively increased or decreased fermentation of OM in 
the rumen and formation of microbial products. This use of $[\mathrm{VFA}]$ to evaluate treatment effects implicitly assumes that all other nontreatment factors that affect concentration are equivalent among treatments. Such nontreatment factors can include absorption and passage of VFA, as well as the amount of ruminal liquid into which the mass of VFA is diluted. However, a recent study reported altered interpretation of treatment effects when ruminal data were evaluated as [VFA] or as pool size or moles of VFA (VFAmol; Hall, 2013). The differences between the response variables were apparently due to variation in rumen liquid amounts. Diluted into differing liquid amounts, [VFA] measurements were not on the equivalent liquid amount basis needed to compare treatments, whereas VFAmol or VFA molar percentages are unaffected by digesta liquid amount.

For [VFA] to be useful for assessing treatment effects and rumen function, measures of rumen liquid volume are needed. However, use of ruminal liquid markers is indirect, they need time to equilibrate (Teeter and Owens, 1983) and will not differentiate between marker passage from the rumen and dilution of marker due to influx of liquid into the rumen. Manual rumen emptying to obtain a direct measurement is laborious and cannot be done repeatedly in short time frames without disturbing rumen function (D. K. Combs, University of Wisconsin, personal communication). Two key questions arise regarding rumen liquid amount: what factors affect it and can it be estimated in some relatively noninvasive way? In addition to direct water consumption or passage of liquid to the abomasum, ruminal liquid amount is driven primarily by the moles of soluble materials present and the osmotic gradient between rumen fluid and blood (Dobson, 1984). If rumen fluid is relatively hypotonic to blood, water is absorbed out of the rumen, whereas if rumen fluid is relatively hypertonic, water is absorbed across the epithelium and into the rumen (Tabaru et al., 1990). Ruminal entry or exit of water has the effect of diluting or concentrating ruminal solutes, and so affects ruminal concentration values. Solutes that affect rumen fluid osmolality include soluble minerals, organic acids, ammonia, AA, and soluble carbohydrates, with VFA representing 30 to $40 \%$ of the total (Warner and Stacy, 1965; Girard et al., 2009).

The objectives of this study were to investigate the variation in and relationships among [VFA], VFAmol, and rumen digesta liquid amount (LIQ) using individual lactating cow data measured in 7 separate feeding trials. Additionally, ruminal analyte concentrations and animal measures were evaluated to determine their potential for predicting LIQ and VFAmol without requiring rumen emptying or use of markers.

\section{MATERIALS AND METHODS}

\section{Experimental Design}

A data set of individual cow observations $(\mathrm{n}=175)$ from 7 separate lactating cow feeding trials performed with ruminally cannulated cows was used in the evaluations. Feeding trials were included if they provided data on rumen liquid amount and concentrations of VFA determined at the same time of day. The trials were performed in different years with different treatment diets (Table 1) and largely used different animals. The experimental diets were corn silage- and alfalfa silagebased, with the exception of study G, in which grass hay or pasture was offered. Six of the studies were conducted at the US Dairy Forage Research Center farm (Prairie du Sac, WI) and 1 was conducted at Purdue University (West Lafayette, IN). All animals were maintained under protocols approved by the Institutional Animal Care and Use Committees of the University of Wisconsin or of Purdue University.

Rumen emptying was performed $2 \mathrm{~h}$ after feeding for each cow on $1 \mathrm{~d}$ of each period, or after morning milking for cows in study G. Rumen contents were manually removed via the rumen cannula and placed

Table 1. Lactating cow study descriptions

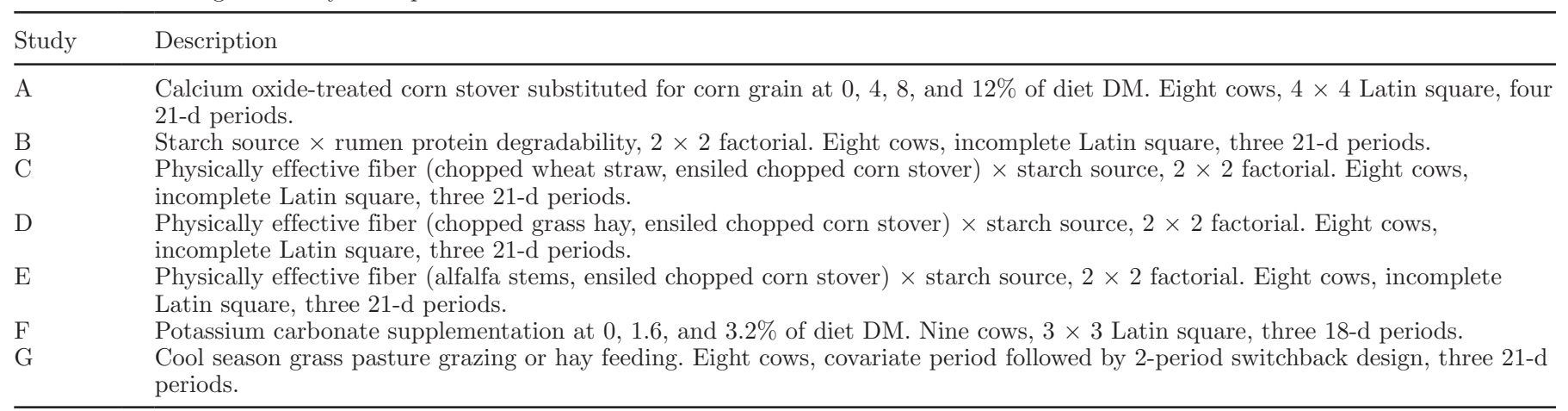


into clean, tared 132-L plastic trash cans and 18.9-L buckets. Every 10th handful of digesta was put in the smaller bucket to provide a $10 \%$ subsample. Digesta weights were recorded, and digesta in the trash can was replaced into the cow from which it came. The $10 \%$ subsamples were mixed thoroughly by hand and three 1,000- to 1,200 -g subsamples per cow were transferred to aluminum pans to be dried in a forced-air oven. After $1 \mathrm{~d}$, samples were mixed and crusts broken to facilitate drying. For studies A, B, C, D, E, and G, samples were dried at $45^{\circ} \mathrm{C}$ for approximately $3 \mathrm{~d}$, until there was no further loss of weight. In study $\mathrm{F}$, samples were dried at $55^{\circ} \mathrm{C}$ for $48 \mathrm{~h}$. Dry weights were recorded and used to calculate digesta DM weight, loss on drying (liquid weight; LIQ), and DM \%.

Ruminal fluid samples were collected $2 \mathrm{~h}$ postfeeding on a day separate from the rumen emptying during collection periods of all studies except for study G. Ruminal [VFA] were determined separately from LIQ because the original intent of the studies was to analyze ruminal concentrations as a time course separate from the rumen liquid amount data. Rumen fluid samples (total $\sim 500 \mathrm{~mL}$ ) for VFA analysis were obtained via ruminal cannulas. Ruminal fluid was collected from the craniad, ventral, and caudal areas of the rumen for studies B, C, and F, and from the ventral areas for studies A, D, and E. Samples were immediately capped and inverted to mix. Samples were filtered through 4 layers of cheesecloth, poured into $20-\mathrm{mL}$ scintillation vials, and immediately frozen at $-20^{\circ} \mathrm{C}$ until analysis. In study $\mathrm{F}$, a $20-\mathrm{mL}$ subsample was acidified with $4 \mathrm{~mL}$ of $25 \%$ (wt/ vol) metaphosphoric acid before freezing to be used for VFA analysis, and another unacidified subsample was collected and frozen. For study G, whole rumen content samples were subsampled during rumen emptying and frozen at $-20^{\circ} \mathrm{C}$; rumen fluid was obtained from thawed digesta samples after squeezing them through 4 layers of cheesecloth. For VFA analysis, rumen fluid samples from all samples except study $\mathrm{F}$ were thawed at room temperature (approximately $23^{\circ} \mathrm{C}$ ) and centrifuged at $12,000 \times g$ for $10 \mathrm{~min}$. For all studies except F, ruminal fluid concentrations of VFA were analyzed by HPLC (Weimer et al., 1991). Ruminal VFA for study $\mathrm{F}$ were analyzed by GC (Erwin et al., 1961).

Total VFA was calculated for each cow in each period as the sum of the millimolar or mole values for acetate, propionate, butyrate, and valerate. Moles of total VFA were calculated as the VFA $(\mathrm{mmol} / \mathrm{L}) \times$ rumen liquid $(\mathrm{L}) \times 1(\mathrm{~mol}) / 1,000(\mathrm{mmol})$. It was assumed that $1 \mathrm{~kg}$ of digesta liquid equaled $1 \mathrm{~L}$.

Mineral analyses and osmolality measurements were performed on the supernatant of unacidified rumen fluid samples centrifuged at $11,800 \times g$ for $45 \mathrm{~min}$ at $5^{\circ} \mathrm{C}$. Minerals were analyzed using an inductively coupled plasma optical emission spectrometer (Optima 5300DV, PerkinElmer, Waltham, MA; AOAC International, 1998; method 953.01). Total soluble minerals $(\mathrm{mg} / \mathrm{kg})$ in the rumen fluid was the sum of $\mathrm{B}, \mathrm{Ca}, \mathrm{Cl}, \mathrm{Cu}, \mathrm{Fe}$, $\mathrm{K}, \mathrm{Mg}, \mathrm{Na}, \mathrm{P}, \mathrm{S}$, and $\mathrm{Zn}$ concentrations. Osmolality was measured as freezing point depression (model 5520 Vapor Pressure Osmometer, Wescor Inc., Logan, UT).

\section{Statistical Analysis}

Similarity of studies for DMI, milk production, BW, [VFA], VFAmol, LIQ, rumen liquid osmolality, [VFA]:osmolality, concentration of soluble minerals in the rumen liquid, and rumen digesta DM \% were evaluated, with study as the sole dependent variable. Mean separation was performed using the Tukey-Kramer procedure.

Within individual studies, simple regression analyses were performed to describe relationships between pairs of variables ([VFA] and VFAmol, [VFA] and LIQ, VFAmol and LIQ). Also within individual studies, backward stepwise regression was performed using cow and ruminal measure data to determine which factors were significant for prediction of LIQ and VFAmol; factors were retained at $P<0.10$.

Regression analyses across all studies were performed using mixed models with "study" as a discrete random variable (St-Pierre, 2001). One set of regressions using 175 individual cow observations evaluated pairs of variables ([VFA] and VFAmol, [VFA] and LIQ, VFAmol and LIQ). Another set of regression analyses for prediction of LIQ and VFAmol was performed by running multiple iterations and removing the least significant variable at each iteration. Independent variables included in the analyses included DMI, milk production, BW, [VFA], rumen liquid osmolality, and concentrations of $\mathrm{B}, \mathrm{Ca}, \mathrm{Cl}, \mathrm{Cu}, \mathrm{Fe}, \mathrm{K}, \mathrm{Mg}, \mathrm{Mn}, \mathrm{Na}, \mathrm{P}, \mathrm{S}$, and $\mathrm{Zn}$ in rumen liquid. Study $\mathrm{G}$ was omitted from the regression development because it lacked DMI data, giving an $\mathrm{n}=146$ for these regression analyses. Selection for a smaller Bayesian information criterion (BIC) value can be used to select models that avoid inclusion of an excessive number of parameters (Littell et al., 2006). The BIC applies a heavier penalty for inclusion of an increasing number of parameters than does Akaike's information criterion. Variables were retained in the model if $P<0.20$, or if removal of a variable gave an increase in the BIC of 5 or more, or if removal of the variable had a $>5 \%$ effect on the result, and decreased the BIC by less than 2. The square root of the covariance parameter estimates for "study" and the residual are presented.

Regression equations for LIQ and VFAmol predictions were evaluated by regressing residuals (observed 
values minus predicted values) on the predicted values (St-Pierre, 2003). Predicted values were centered by subtracting the mean of all predicted values from each prediction. This makes the estimates of slope and intercept in the regression orthogonal and independent. Mean biases were assessed using the intercepts of the regression equations, and the slopes of the regression equations were used to determine the presence of linear biases. All statistical procedures were performed using SAS (ver. 9.3, SAS Institute, 2013). "Range" values were calculated as the maximum value minus the minimum value.

\section{RESULTS AND DISCUSSION}

\section{Feeding Study Data}

The 7 lactating cow studies differed in factors related to both animal and ruminal measures. The DMI, milk production, and BW of cows differed among studies ( $P$ $<0.01$, for all; Table 2). The mean values from each study ranged from 21.0 to $25.4 \mathrm{~kg}$ for DMI (in 6 studies; no intake data was available for the pasture study, G), 7.1 to $41.5 \mathrm{~kg}$ for milk production, and 552 to $643 \mathrm{~kg}$ for BW. Cows on the grazing study $(\mathrm{G})$ had the lowest milk production and numerically lowest BW.

All ruminal measures but one differed across studies (Table 3). Rumen liquid osmolality only tended to dif- fer across studies $(P=0.08)$, with a range of 280 to 296 $\mathrm{mmol} / \mathrm{kg}$ for mean within-study values. The limited range of osmolality values is a function of homeostasis, with ruminal osmolality modulated to be similar to the osmolality of blood, which is under homeostatic control (Dobson, 1984) and is between 280 to $300 \mathrm{mmol} / \mathrm{kg}$ (Merck Veterinary Manual, 1991). The osmolality and ruminal digesta DM \% had the numerically smallest coefficients of variation (CV) within study (average $\mathrm{CV}$ of 7.3 and $7.8 \%$, respectively), further reflecting the relatively greater consistency of these values within and across studies. The VFAmol had the numerically largest within-study CV (averaging 22.5\%), whereas the remaining ruminal measures were intermediate (average $\mathrm{CV}$ were $[\mathrm{VFA}]=12.8 \%$; soluble mineral concentration $=10.5 \% ;[\mathrm{VFA}]$ :osmolality $=10.2 \%$; rumen liquid $\mathrm{kg}$ $=15.3 \%)$. Within individual studies, the difference between minimum and maximum LIQ values ranged from 35 to $48 \mathrm{~kg}$ of liquid.

Study $\mathrm{F}$ was the only study in which mineral supplementation was the experimental treatment. Cows in that study had the smallest or numerically smallest values for [VFA], VFAmol, and LIQ, which may relate to measured DMI, which was also numerically smallest for this study (Table 3). In study F, the average concentration of soluble minerals in the rumen fluid was more than $12 \%$ greater than those of the other studies in which TMR were fed. The change in soluble mineral

Table 2. Dry matter intake, milk production, and BW by study

\begin{tabular}{|c|c|c|c|c|c|c|c|}
\hline Study & Mean & $\mathrm{SD}$ & Minimum & Maximum & $\mathrm{CV}, \%$ & $\mathrm{SED}^{1}$ & $P$-value ${ }^{2}$ \\
\hline \multicolumn{8}{|c|}{ DMI, $\mathrm{kg}$} \\
\hline A & $23.7^{\mathrm{y}}$ & 3.3 & 16.9 & 29.6 & 13.9 & \multirow[t]{7}{*}{0.83} & \multirow[t]{7}{*}{$<0.01$} \\
\hline B & $25.4^{\mathrm{y}}$ & 2.0 & 21.2 & 29.6 & 7.9 & & \\
\hline $\mathrm{C}$ & $23.4^{x y}$ & 3.4 & 18.3 & 29.8 & 14.5 & & \\
\hline $\mathrm{D}$ & $23.9^{\mathrm{y}}$ & 3.5 & 17.6 & 31.5 & 14.6 & & \\
\hline $\mathrm{E}$ & $22.7^{\mathrm{xy}}$ & 2.3 & 18.4 & 27.8 & 10.1 & & \\
\hline $\mathrm{F}$ & $21.0^{\mathrm{x}}$ & 2.8 & 16.2 & 25.7 & 13.3 & & \\
\hline $\mathrm{G}$ & - & - & - & - & - & & \\
\hline \multicolumn{8}{|c|}{ Milk, kg } \\
\hline A & $35.1^{\mathrm{y}}$ & 4.6 & 24.9 & 42.6 & 13.1 & \multirow[t]{7}{*}{1.51} & \multirow[t]{7}{*}{$<0.01$} \\
\hline B & $41.5^{\mathrm{z}}$ & 4.8 & 32.6 & 51.4 & 11.6 & & \\
\hline $\mathrm{C}$ & $37.5^{\mathrm{yz}}$ & 3.6 & 32.3 & 44.0 & 9.6 & & \\
\hline D & $40.1^{\mathrm{z}}$ & 10.3 & 18.2 & 55.8 & 25.7 & & \\
\hline $\mathrm{E}$ & $33.9^{\mathrm{y}}$ & 4.9 & 21.0 & 41.2 & 14.5 & & \\
\hline $\mathrm{F}$ & $26.3^{\mathrm{x}}$ & 3.3 & 21.6 & 32.9 & 12.5 & & \\
\hline $\mathrm{G}$ & $7.1^{\mathrm{w}}$ & 2.64 & 1.4 & 12.2 & 37.2 & & \\
\hline \multicolumn{8}{|c|}{$\mathrm{BW}, \mathrm{kg}$} \\
\hline A & $636.5^{y}$ & 105.2 & 489.9 & 857.3 & 16.5 & \multirow[t]{7}{*}{21.8} & \multirow[t]{7}{*}{$<0.01$} \\
\hline B & $643.0^{\mathrm{y}}$ & 43.7 & 574.9 & 722.4 & 6.8 & & \\
\hline $\mathrm{C}$ & $625.9^{\mathrm{y}}$ & 113.5 & 478.5 & 824.4 & 18.1 & & \\
\hline $\mathrm{D}$ & $590.0^{x y}$ & 47.3 & 494.4 & 655.5 & 8.0 & & \\
\hline $\mathrm{E}$ & $579.0^{\mathrm{xy}}$ & 42.8 & 505.8 & 673.6 & 7.4 & & \\
\hline $\mathrm{F}$ & $585.4^{x y}$ & 49.1 & 518.0 & 671.3 & 8.4 & & \\
\hline G & $552.3^{x}$ & 65.1 & 462.7 & 678.1 & 11.8 & & \\
\hline
\end{tabular}


HALL ET AL.

Table 3. Rumen measures by study

\begin{tabular}{|c|c|c|c|c|c|c|c|}
\hline Study & Mean & $\mathrm{SD}$ & Minimum & Maximum & $\mathrm{CV}, \%$ & $\mathrm{SED}^{1}$ & $P$-value ${ }^{2}$ \\
\hline \multicolumn{8}{|c|}{ VFA, $\mathrm{m} M$} \\
\hline $\mathrm{A}$ & $161.4^{\mathrm{Z}}$ & 17.1 & 133.1 & 193.5 & 10.6 & \multirow[t]{7}{*}{5.3} & \multirow[t]{7}{*}{$<0.01$} \\
\hline B & $146.4^{\mathrm{xyz}}$ & 20.3 & 93.3 & 193.4 & 13.9 & & \\
\hline $\mathrm{C}$ & $161.7^{\mathrm{z}}$ & 21.2 & 128.4 & 198.9 & 13.1 & & \\
\hline $\mathrm{D}$ & $160.4^{\mathrm{z}}$ & 18.1 & 134.1 & 197.5 & 11.3 & & \\
\hline $\mathrm{E}$ & $153.9^{\mathrm{yz}}$ & 22.0 & 113.5 & 203.7 & 14.3 & & \\
\hline $\mathrm{F}$ & $131.1^{\mathrm{x}}$ & 22.0 & 94.0 & 191.8 & 16.8 & & \\
\hline G & $143.2^{\mathrm{xy}}$ & 13.6 & 121.1 & 163.8 & 9.5 & & \\
\hline \multicolumn{8}{|c|}{ VFA, mol } \\
\hline A & $12.8^{\mathrm{yz}}$ & 2.3 & 8.8 & 18.2 & 18.0 & \multirow[t]{7}{*}{0.69} & \multirow[t]{7}{*}{$<0.01$} \\
\hline $\mathrm{B}$ & $11.2^{\mathrm{xy}}$ & 2.9 & 5.9 & 16.6 & 25.9 & & \\
\hline $\mathrm{C}$ & $13.5^{\mathrm{z}}$ & 3.3 & 8.3 & 21.0 & 24.4 & & \\
\hline D & $12.2^{\mathrm{xyz}}$ & 2.6 & 9.1 & 20.1 & 21.3 & & \\
\hline $\mathrm{E}$ & $10.5^{\mathrm{x}}$ & 2.0 & 6.6 & 15.1 & 19.0 & & \\
\hline $\mathrm{F}$ & $8.2^{\mathrm{w}}$ & 2.5 & 4.2 & 14.3 & 30.5 & & \\
\hline $\mathrm{G}$ & $10.0^{\mathrm{wx}}$ & 1.8 & 6.8 & 12.8 & 18.0 & & \\
\hline \multicolumn{8}{|c|}{ Soluble minerals, $\mathrm{mg} / \mathrm{kg}$} \\
\hline A & $5,284^{\mathrm{y}}$ & 569 & 4,089 & 6,235 & 10.8 & \multirow[t]{7}{*}{161} & \multirow[t]{7}{*}{$<0.01$} \\
\hline B & $4,989^{x y}$ & 510 & 4,478 & 6,571 & 10.2 & & \\
\hline $\mathrm{C}$ & $4,973^{\mathrm{xy}}$ & 404 & 4,097 & 6,139 & 8.1 & & \\
\hline $\mathrm{D}$ & $4,823^{\mathrm{x}}$ & 549 & 3,909 & 6,728 & 11.4 & & \\
\hline $\mathrm{E}$ & $5,175^{\mathrm{xy}}$ & 597 & 4,283 & 6,729 & 11.5 & & \\
\hline $\mathrm{F}$ & $5,946^{\mathrm{z}}$ & 628 & 4,416 & 7,491 & 10.6 & & \\
\hline $\mathrm{G}$ & $5,167^{x y}$ & 549 & 3,960 & 6,164 & 10.6 & & \\
\hline \multicolumn{8}{|c|}{ Osmolality, $\mathrm{mmol} / \mathrm{kg}$} \\
\hline A & 285 & 17.1 & 246 & 318 & 6.0 & \multirow[t]{8}{*}{6.0} & \multirow[t]{7}{*}{0.08} \\
\hline B & 284 & 25.7 & 248 & 348 & 9.0 & & \\
\hline $\mathrm{C}$ & 293 & 22.1 & 248 & 333 & 7.5 & & \\
\hline $\mathrm{D}$ & 295 & 17.9 & 270 & 331 & 6.1 & & \\
\hline $\mathrm{E}$ & 296 & 22.9 & 248 & 349 & 7.7 & & \\
\hline $\mathrm{F}$ & 288 & 22.3 & 261 & 347 & 7.7 & & \\
\hline G & 280 & 19.8 & 239 & 318 & 7.1 & & \\
\hline \multicolumn{7}{|c|}{ [VFA]:osmolality } & \\
\hline A & $0.57^{\mathrm{z}}$ & 0.057 & 0.46 & 0.67 & 10.0 & \multirow[t]{7}{*}{0.015} & \multirow[t]{7}{*}{$<0.01$} \\
\hline $\mathrm{B}$ & $0.52^{\mathrm{y}}$ & 0.055 & 0.35 & 0.58 & 10.6 & & \\
\hline $\mathrm{C}$ & $0.55^{\mathrm{yz}}$ & 0.061 & 0.46 & 0.66 & 11.1 & & \\
\hline $\mathrm{D}$ & $0.54^{\mathrm{yz}}$ & 0.050 & 0.47 & 0.63 & 9.3 & & \\
\hline $\mathrm{E}$ & $0.52^{\mathrm{y}}$ & 0.056 & 0.41 & 0.60 & 10.8 & & \\
\hline $\mathrm{F}$ & $0.45^{\mathrm{x}}$ & 0.056 & 0.35 & 0.55 & 12.4 & & \\
\hline G & $0.51^{\mathrm{y}}$ & 0.037 & 0.46 & 0.59 & 7.3 & & \\
\hline \multicolumn{8}{|c|}{ Liquid, $\mathrm{kg}$} \\
\hline A & $78.7^{\mathrm{yz}}$ & 9.6 & 60.3 & 95.5 & 12.2 & \multirow[t]{7}{*}{3.2} & $<0.01$ \\
\hline $\mathrm{B}$ & $75.7^{\mathrm{xyz}}$ & 11.8 & 55.2 & 99.5 & 15.6 & & \\
\hline $\mathrm{C}$ & $82.7^{\mathrm{z}}$ & 13.9 & 63.2 & 111.6 & 16.8 & & \\
\hline D & $76.3^{\mathrm{xyz}}$ & 13.3 & 55.1 & 101.9 & 17.4 & & \\
\hline $\mathrm{E}$ & $68.1^{\mathrm{wx}}$ & 9.1 & 49.7 & 84.1 & 13.4 & & \\
\hline $\mathrm{F}$ & $61.7^{\mathrm{w}}$ & 10.7 & 41.4 & 80.0 & 17.3 & & \\
\hline G & $69.9^{\text {wxy }}$ & 10.1 & 53.0 & 92.8 & 14.4 & & \\
\hline Digest & & & & & & & \\
\hline A & $15.3^{\text {xyz }}$ & 1.02 & 13.0 & 17.9 & 6.7 & 0.33 & $<0.01$ \\
\hline B & $15.1^{\mathrm{xy}}$ & 1.36 & 11.7 & 16.7 & 9.0 & & \\
\hline $\mathrm{C}$ & $16.2^{\mathrm{z}}$ & 0.94 & 13.8 & 18.2 & 5.8 & & \\
\hline $\mathrm{D}$ & $15.3^{\mathrm{xyz}}$ & 1.07 & 13.5 & 18.1 & 7.0 & & \\
\hline $\mathrm{E}$ & $15.6^{\mathrm{yz}}$ & 1.13 & 12.4 & 17.1 & 7.2 & & \\
\hline $\mathrm{F}$ & $14.4^{\mathrm{x}}$ & 1.64 & 10.6 & 18.1 & 11.4 & & \\
\hline $\mathrm{G}$ & $11.4^{\mathrm{w}}$ & 0.89 & 9.5 & 12.7 & 7.8 & & \\
\hline
\end{tabular}

${ }^{\mathrm{w}-\mathrm{z}}$ Studies within measurement type with different superscripts differ, $P<0.05$.

${ }^{1}$ Standard error of the difference.

${ }^{2} P$-values and SED refer to effects of study.

concentration may offer some explanation as to why study $\mathrm{F}$ had a lower proportion ([VFA]:osmolality = 0.45 ; Table 3 ) of rumen fluid osmolality accounted for by VFA $(P<0.05)$. It would seem likely that with ru- minal osmolality held fairly constant relative to blood, an increase in mass of dietary soluble mineral entering the rumen would alter the ratio of mineral to VFA and the proportional contribution to osmolality from VFA 
if VFA production was unaffected. The other studies that did not use minerals or buffers as treatments had [VFA]:osmolality values between 0.51 and 0.57 . These values are higher than average values reported in the literature, but the highest [VFA]:osmolality measurements do occur within 1 to $2 \mathrm{~h}$ postfeeding (C. Girard, Agriculture and Agri-Food Canada, Sherbrooke, Quebec, personal communication), which is within the time frame in which samples were obtained in the 7 studies. The rumen digesta DM \% was lowest on the pasture study $(P<0.05)$.

\section{Relationships Among [VFA], VFAmol, and Rumen Liquid Amount}

Individual studies all showed an increase in LIQ with increasing VFAmol, with the change in LIQ per VFA mole of roughly the same magnitude across studies (Figure 1, Table 4). The increase in LIQ per mole of VFA was $3.76 \mathrm{~kg}$ across studies, with a range of individual study values from 2.90 to $4.77 \mathrm{~kg} / \mathrm{mol}$ of VFA and $\mathrm{R}^{2}$ ranging from 0.42 to 0.80 . The LIQ responses to changing VFAmol are consistent with the documented flux in ruminal liquid relative to changes in amount of intraruminal solute: as amounts of intraruminal solute increase or decrease, amounts of ruminal liquid do the same (Dobson, 1984; Tabaru et al., 1990). Factors that alter the moles of ruminal VFA include rate of fermentation, amount of fermentable or soluble substrate, rate of feed consumption, VFA absorption, and liquid or solid passage. Changes in LIQ relative to VFAmol may have implications for prediction of liquid passage if introduction of solute from consumed feed and fermentation drives influx of water into the rumen. This would help to explain the temporal aspect of liquid passage described by Gasa et al. (1991).

In contrast, the relationships of [VFA] to LIQ within the studies were very weak $\left(\mathrm{R}^{2}\right.$ from $<0.01$ to 0.31 ; Figure 2, Table 4), with slopes ranging from -0.009 to $1.14 \mathrm{~m} M \mathrm{VFA} / \mathrm{kg}$ of rumen liquid. Within and across studies, numerically similar [VFA] occurred in LIQ amounts that could differ by more than $30 \mathrm{~kg}$ (Figure 2 ). These results show that similar concentrations of VFA can occur in differing dilution volumes of ruminal liquid within studies. The scatter rather than vertical clustering of the LIQ data points also indicates that this measure is not consistent within individual cows across periods within study. The range in LIQ values (maximum minus minimum values) within cow and within study averaged $12.7 \mathrm{~kg}(\mathrm{SD}=7.1$, minimum: $0.72 \mathrm{~kg}$, maximum $31.4 \mathrm{~kg}$ ). Therefore, accounting for cow effects will not adjust for the variability in LIQ, because LIQ is not consistent within cow. The poor relationship between LIQ and [VFA] is likely a func- tion of the control of ruminal osmolality: rumen fluid is on an osmotic gradient with blood, and its osmolality stays similar to that of blood. The homeostatic control exerted on the osmolality of blood indirectly modulates the osmolality of rumen fluid through entry or exit of water to adjust for changes in moles of ruminal solute (Dobson, 1984; Tabaru et al., 1990). This has a damping effect on changes in concentrations caused by addition or removal of moles of solutes, including VFA. This damping of change in [VFA] compared with VFAmol is also seen in the average within-study CV, with [VFA] having a CV (12.8\%) almost half that of VFAmol $(22.5 \%)$.

The relationship between [VFA] and VFAmol was weaker than the relationship between LIQ and VFAmol (Figure 3, Table 4). The $\mathrm{R}^{2}$ ranged from 0.26 to 0.78 and slopes ranged from 3.60 to $8.18 \mathrm{VFA} \mathrm{m} M / \mathrm{mol}$, with an average slope of 5.80 across all studies. However, the relationship between [VFA] and VFAmol changed with LIQ (Figure 4; graph only, no data analysis), which is an inherent relationship based on the mathematics of how pool size is calculated: VFA moles $=$ VFA $(\mathrm{mmol} / \mathrm{L}) \times$ rumen liquid $(\mathrm{L}) \times 1(\mathrm{~mol}) / 1,000$ (mmol). If we rearrange the equation to describe the proportional relationship of [VFA] to VFAmol relative to LIQ, we have [VFA]/VFAmol $=1,000 / \mathrm{LIQ}$. The ratio of [VFA] to VFAmol varies when the same moles of VFA are diluted into different volumes, which give different [VFA]. The ratio ranged from 9.0 to 24.1 with an average within-study range of 8.2 (within-study range minimum: 6.1, maximum: 11.6). This variation in the relationship between [VFA] and VFAmol as LIQ changed further emphasizes the risk of using [VFA] to make inferences regarding the effect of treatment on

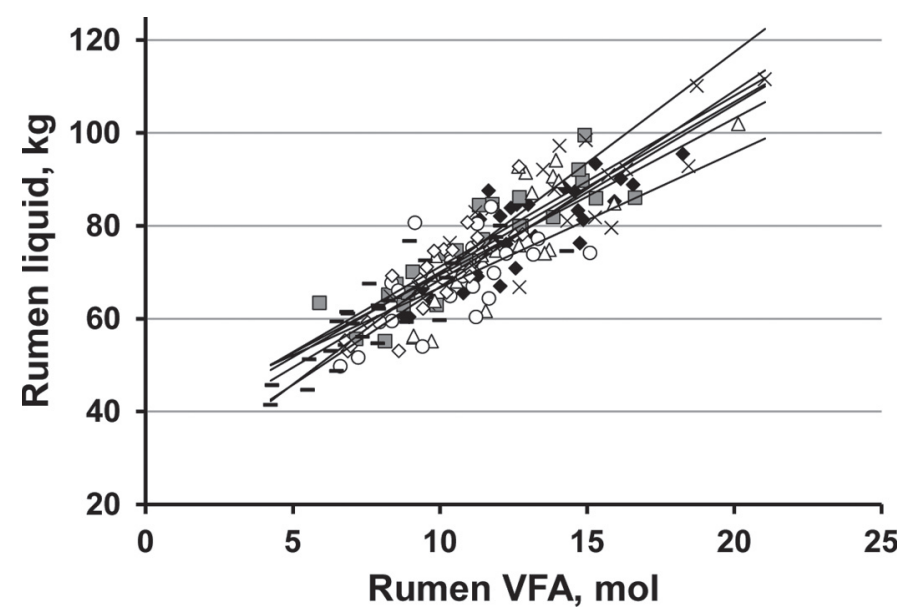

Figure 1. Relationship in the rumen between moles of VFA and amount of liquid. Regression lines are drawn through individual studies $(\mathrm{n}=175$; studies: $\mathrm{A}=\bullet, \mathrm{B}=\mathbf{\square}, \mathrm{C}=\times, \mathrm{D}=\Delta, \mathrm{E}=\mathrm{O}, \mathrm{F}=-$, and $G=\diamond)$. 


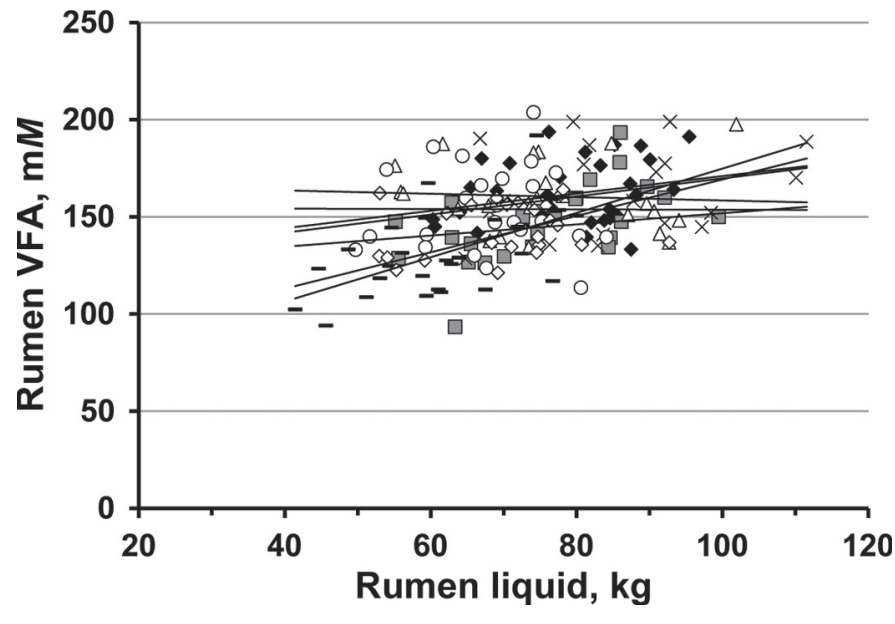

Figure 2. Relationship in the rumen between amount of liquid and millimolar concentration of VFA. Regression lines are drawn through individual studies $(\mathrm{n}=175$; studies: $\mathrm{A}=\boldsymbol{\nabla}, \mathrm{B}=\mathbf{\square}, \mathrm{C}=\times, \mathrm{D}=\Delta$, $\mathrm{E}=\mathrm{O}, \mathrm{F}=-$, and $\mathrm{G}=\diamond)$. ruminal fermentation for even relative differences in microbial product formation.

\section{Implications for Use of VFA Concentration or VFA Pool Size to Evaluate Treatment Effects}

To make valid inferences about treatment effects, the values for a given response variable must be on an equivalent basis across all treatments. For comparison of concentrations, that equivalence includes being in similar or known volumes. Because the measured [VFA] in the 7 studies were found in liquid amounts that varied within study by 34 to $48 \mathrm{~kg}$, it is clear that the assumption of equivalence was incorrect, which voids the utility of [VFA] for evaluating treatment effects on ruminal fermentation. The problem with using ruminal VFA concentrations is analogous to attempting to use concentration results from laboratory analyses performed on samples with no internal standard and with no knowledge of the varying dilutions used to

Table 4. Results of simple regression analyses among ruminal VFA concentration, VFA pool size, and liquid amount for individual studies and across studies $^{1}$

\begin{tabular}{lcccrrr}
\hline Study & $\mathrm{n}$ & $\begin{array}{c}\text { Coefficient } \\
(\mathrm{SE})\end{array}$ & $\begin{array}{c}\text { Intercept } \\
(\mathrm{SE})\end{array}$ & $\mathrm{R}^{2}$ & $\mathrm{RMSE}^{2}$ & $\mathrm{CV}, \%$ \\
\hline $\mathrm{Y}=$ Liquid kg, X = VFA mol & & & & & \\
$\mathrm{A}$ & 31 & $3.36(0.45)$ & $35.9(5.78)$ & 0.66 & 5.68 & 7.21 \\
$\mathrm{~B}$ & 24 & $3.68(0.40)$ & $34.5(4.58)$ & 0.80 & 5.45 & 7.20 \\
$\mathrm{C}$ & 23 & $3.66(0.47)$ & $33.4(6.52)$ & 0.74 & 7.25 & 8.76 \\
$\mathrm{D}$ & 23 & $4.22(0.65)$ & $24.8(8.08)$ & 0.67 & 7.83 & 10.26 \\
$\mathrm{E}$ & 24 & $2.90(0.72)$ & $37.7(7.73)$ & 0.42 & 7.04 & 10.33 \\
$\mathrm{~F}$ & 27 & $3.77(0.42)$ & $30.7(3.62)$ & 0.76 & 5.35 & 8.67 \\
$\mathrm{G}$ & 23 & $4.77(0.58)$ & $22.0(5.96)$ & 0.76 & 5.04 & 7.21 \\
All studies & 175 & $3.76(0.17)$ & $31.2(1.97)$ & &
\end{tabular}

$\begin{array}{lr}\mathrm{Y}=\text { VFA } \mathrm{m} M, \mathrm{X}=\text { Liquid } \mathrm{kg} \\ \mathrm{A} & 31 \\ \mathrm{~B} & 24 \\ \mathrm{C} & 23 \\ \mathrm{D} & 23 \\ \mathrm{E} & 24 \\ \mathrm{~F} & 27 \\ \mathrm{G} & 23 \\ \text { All studies } & 175\end{array}$

Square root of variance components: study $=0.91 ;$ residual $=6.25$

$\mathrm{Y}=\mathrm{VFA} \mathrm{m} M, \mathrm{X}=\mathrm{VFA} \mathrm{mol}$

\begin{tabular}{|c|c|c|c|c|c|c|}
\hline A & 31 & $5.62(0.88)$ & $89.7(11.4)$ & 0.58 & 11.2 & 6.96 \\
\hline B & 24 & $6.09(0.77)$ & $78.2(8.9)$ & 0.74 & 10.6 & 7.24 \\
\hline $\mathrm{C}$ & 23 & $4.79(0.95)$ & $97.2(13.1)$ & 0.55 & 14.6 & 9.00 \\
\hline $\mathrm{D}$ & 23 & $3.60(1.31)$ & $116.4(16.4)$ & 0.26 & 15.9 & 9.89 \\
\hline $\mathrm{E}$ & 24 & $8.18(1.53)$ & $68.1(16.3)$ & 0.57 & 14.8 & 9.63 \\
\hline $\mathrm{F}$ & 27 & $7.85(0.83)$ & $66.6(7.1)$ & 0.78 & 10.5 & 8.01 \\
\hline G & 23 & $4.87(1.21)$ & $94.3(12.3)$ & 0.44 & 10.4 & 7.28 \\
\hline All studies & 175 & $5.80(0.36)$ & $86.3(4.4)$ & & & \\
\hline
\end{tabular}

${ }^{1} \mathrm{Y}=$ dependent variable, $\mathrm{X}=$ independent variable, VFA $=$ the sum of acetate, propionate, butyrate, and valerate.

${ }^{2}$ Root mean square error. 


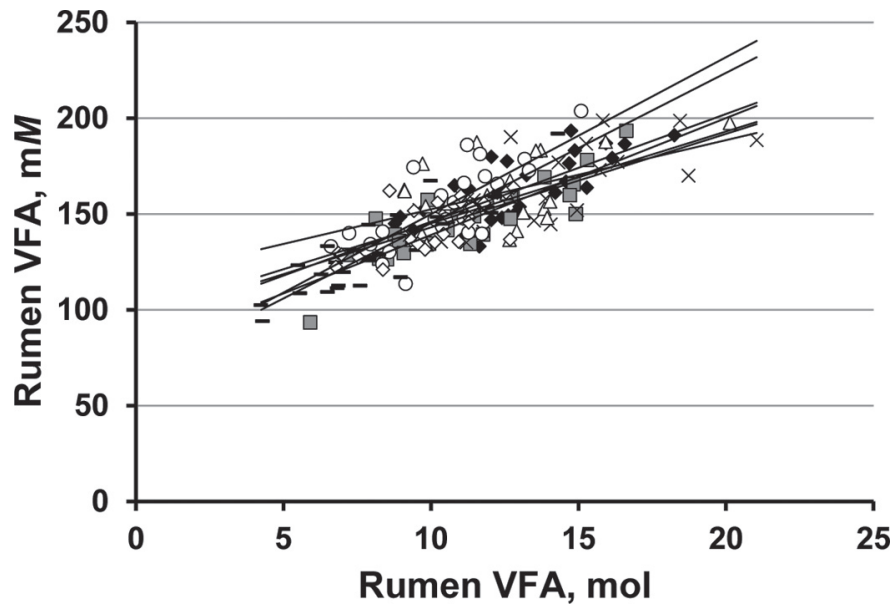

Figure 3. Relationship in the rumen between moles of VFA and millimolar concentrations of VFA. Regression lines are drawn through individual studies $(\mathrm{n}=175$; studies: $\mathrm{A}=\bullet, \mathrm{B}=\mathbf{\square}, \mathrm{C}=\times, \mathrm{D}=\Delta$, $\mathrm{E}=\mathrm{O}, \mathrm{F}=-$, and $\mathrm{G}=\diamond)$.

prepare the samples. Without the dilution information, one does not know how the sample values relate to each other. The use of [VFA] is further compromised if treatments affect ruminal liquid amount (Hall, 2013), as the relationship between concentrations and effect of treatments on VFA pool size may be further changed. Ruminal VFA concentrations or $\mathrm{pH}$ can still be used directly to describe existing conditions of the rumen environment as related to treatment.

Issues with the use of ruminal VFA concentrations to quantitatively evaluate ruminal fermentation have been reported previously. It has been noted that ruminal [VFA] are the result of production and absorption and so do not necessarily reflect fermentation rates (Dijkstra et al., 1993). Others have suggested that absorption and passage of the VFA may be responsible for the lack of relationship between ruminally digested OM and VFA concentrations (Oba and Allen, 2003). Efforts have been made to relate ruminal concentrations to rates of VFA production, but the coefficient of variation was high (Leng and Brett, 1966). Sutton et al. (2003) stated that ruminal concentrations of VFA "must be treated with some caution" for predicting ruminal VFA production because the relationship between concentration and production changed across studies, with changing rumen volume being an issue. That rumen liquid volume changes by sampling time and treatment has been documented in several studies (e.g., Gasa et al., 1991; Sutton et al., 2003). If not measured and accounted for, differing ruminal liquid volumes nullify our ability to accurately interpret the meaning of ruminal concentrations in terms of treatment effects on the production or yield of microbial

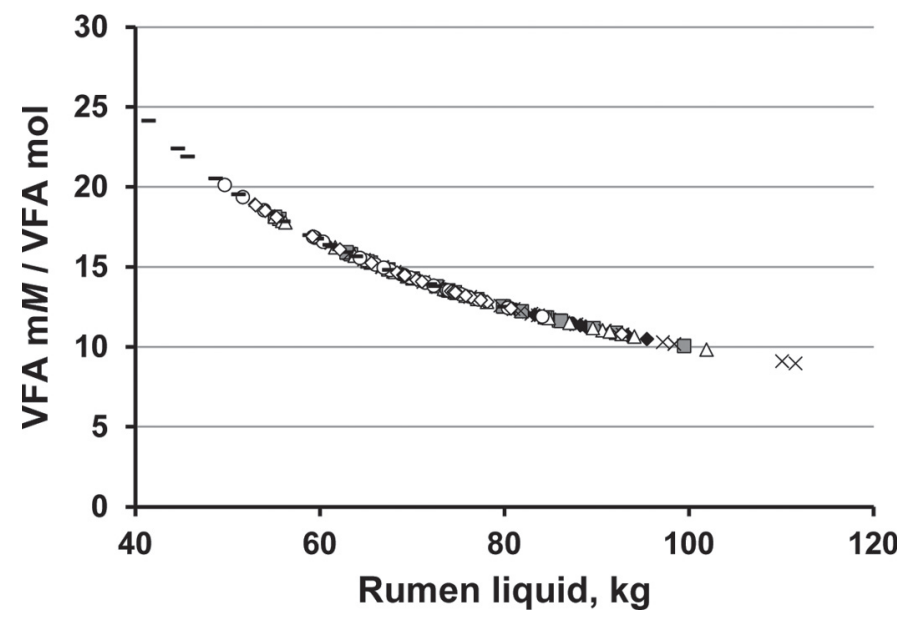

Figure 4. Relationship in the rumen between rumen liquid amount and the ratio of millimolar concentration of VFA to moles of VFA (n $=175$; studies: $\mathrm{A}=\bullet, \mathrm{B}=\mathbf{\square}, \mathrm{C}=\times, \mathrm{D}=\Delta, \mathrm{E}=\mathrm{O}, \mathrm{F}=-$, and $\mathrm{G}=\diamond)$.

fermentation products. Conclusions drawn from ruminal concentration data regarding rumen function or treatment effects will need to be revisited with some more accurate method of evaluation.

The use of ruminal VFA pool size to evaluate treatment effects on ruminal fermentation is not without issues. The pool size measures are on a known volume basis that does allow their comparison at specific time points. However, without accounting for passage, absorption from the rumen, rate of eating, and so on, the pool size data still do not provide a complete picture of product formation from ruminal fermentation.

\section{Predictions of Rumen Liquid Amount and Moles of VFA}

Although it is the most reliable method for determining rumen liquid amounts needed to calculate ruminal VFA pool size, rumen emptying is a laborious process. It cannot be repeated on a given animal on a frequent basis or it may perturb rumen function (D. K. Combs, University of Wisconsin, personal communication). The workload in experiments would be greatly reduced and more frequent estimates of rumen liquid amounts and moles of VFA could be made if rumen liquid amount could be predicted from commonly obtained animal or ruminal measurements. In the present study, LIQ measured $2 \mathrm{~h}$ postfeeding averaged $73.3 \mathrm{~kg}$ across all studies $(\mathrm{SD}=12.9$, minimum: 41.4, maximum: 111.6, range: 70.2). Individual studies differed in which independent variables were significant for prediction of LIQ (Table $5)$. Regression equations for the individual studies had an average $\mathrm{R}^{2}$ of 0.66 and an average root mean square 
Table 5. Independent variables that were retained in regression equations describing ruminal liquid amount and moles of VFA in individual studies $^{1}$

\begin{tabular}{|c|c|c|c|c|c|c|c|c|c|c|c|c|c|c|c|c|c|c|}
\hline Study & DMI & Milk & BW & VFA & B & $\mathrm{Ca}$ & $\mathrm{Cl}$ & $\mathrm{Cu}$ & $\mathrm{Fe}$ & $\mathrm{K}$ & $\mathrm{Mg}$ & $\mathrm{Na}$ & $\mathrm{P}$ & $\mathrm{S}$ & $\mathrm{Zn}$ & Osm & RMSE & $\mathrm{R}^{2}$ \\
\hline \multicolumn{19}{|c|}{ Rumen liquid kg } \\
\hline A & $\mathrm{x}$ & & & & & & & & & & $\mathrm{x}$ & & $\mathrm{x}$ & & $\mathrm{x}$ & & 6.23 & 0.64 \\
\hline $\mathrm{D}$ & $\mathrm{x}$ & & - & & $\mathrm{x}$ & $\mathrm{x}$ & & & & & & & & & & & 10.91 & 0.42 \\
\hline $\mathrm{E}$ & & $\mathrm{x}$ & & & & & $\mathrm{x}$ & $\mathrm{x}$ & $\mathrm{x}$ & & & & $\mathrm{x}$ & $\mathrm{x}$ & & & 5.38 & 0.74 \\
\hline $\mathrm{F}$ & & & $\mathrm{x}$ & & & & & & & $\mathrm{x}$ & $\mathrm{x}$ & $\mathrm{x}$ & & & & $\mathrm{x}$ & 7.49 & 0.62 \\
\hline A & $\mathrm{x}$ & & & $\mathrm{x}$ & & & & & $\mathrm{x}$ & & $\mathrm{x}$ & & $\mathrm{x}$ & & $\mathrm{x}$ & & 1.00 & 0.85 \\
\hline B & & & & & & & $\mathrm{x}$ & & & & $\mathrm{x}$ & $\mathrm{x}$ & & & $\mathrm{x}$ & $\mathrm{x}$ & 1.19 & 0.86 \\
\hline $\mathrm{C}$ & & $\mathrm{x}$ & $\mathrm{x}$ & $\mathrm{x}$ & & & & & & $\mathrm{x}$ & $\mathrm{x}$ & $\mathrm{x}$ & $\mathrm{x}$ & & & & 0.91 & 0.95 \\
\hline $\mathrm{D}$ & $\mathrm{x}$ & & - & & $\mathrm{x}$ & $\mathrm{x}$ & & & $\mathrm{x}$ & & $\mathrm{x}$ & & & $\mathrm{x}$ & & & 1.93 & 0.59 \\
\hline $\mathrm{E}$ & & $\mathrm{x}$ & & $\mathrm{x}$ & & & $\mathrm{x}$ & $\mathrm{x}$ & $\mathrm{x}$ & & $\mathrm{x}$ & & & $\mathrm{x}$ & & & 0.85 & 0.88 \\
\hline $\mathrm{F}$ & & & $\mathrm{x}$ & & & & & & & $\mathrm{x}$ & $\mathrm{x}$ & $\mathrm{x}$ & & & & $\mathrm{x}$ & 0.87 & 0.90 \\
\hline G & - & $\mathrm{x}$ & & $\mathrm{x}$ & & $\mathrm{x}$ & & & $\mathrm{x}$ & & $\mathrm{x}$ & & $\mathrm{x}$ & & & & 0.77 & 0.88 \\
\hline
\end{tabular}

${ }^{1}$ Variables were retained at $P<0.10 . \mathrm{DMI}=\mathrm{DMI}, \mathrm{kg} ; \mathrm{Milk}=$ milk production, $\mathrm{kg} ; \mathrm{BW}=\mathrm{BW}, \mathrm{kg} ; \mathrm{VFA}=\mathrm{ruminal} \mathrm{VFA} \mathrm{m} M ; \mathrm{B}, \mathrm{Ca}, \mathrm{Cl}, \mathrm{Cu}$, $\mathrm{Fe}, \mathrm{K}, \mathrm{Mg}, \mathrm{Na}, \mathrm{P}, \mathrm{S}$, and $\mathrm{Zn}=$ rumen fluid-soluble elements, $\mathrm{mg} / \mathrm{kg}$; Osm = osmolality, mmol $/ \mathrm{kg}$; RMSE = root mean squared error. Dashes indicate data not available from the specific study.

error of 7.12. The mixed model regression analysis for rumen liquid amount $(\mathrm{kg})$ gave the following:

Initial equation:

$$
\begin{gathered}
12.4911+0.3635 \text { milk }(\mathrm{kg})+0.08424 \mathrm{BW}(\mathrm{kg}) \\
+0.1682 \text { VFA }(\mathrm{m} M)-0.01323 \mathrm{Na}(\mathrm{mg} / \mathrm{kg}) \\
-0.00556 \mathrm{~K}(\mathrm{mg} / \mathrm{kg})+0.1439 \mathrm{~S}(\mathrm{mg} / \mathrm{kg}) \\
-1.1302 \mathrm{~B}(\mathrm{mg} / \mathrm{kg}) ;
\end{gathered}
$$

square root of covariance parameter estimates: study $=$ 2.41 , residual $=8.73 ; \mathrm{BIC}=1,084.0$.

Reduced equation:

$$
\begin{gathered}
10.6395+0.3933 \text { milk }(\mathrm{kg})+0.08406 \mathrm{BW}(\mathrm{kg}) \\
+0.1636 \mathrm{VFA}(\mathrm{m} M)-0.01244 \mathrm{Na}(\mathrm{mg} / \mathrm{kg}) \\
-0.00486 \mathrm{~K}(\mathrm{mg} / \mathrm{kg})+0.1091 \mathrm{~S}(\mathrm{mg} / \mathrm{kg}) ;
\end{gathered}
$$

square root of covariance parameter estimates: study $=$ 2.64 , residual $=8.76 ; \mathrm{BIC}=1,087.5$.

As suggested by the covariance parameter estimate for the residual, there was substantial variation related to the individual measurements. The mean and maximum values for residuals were 7.3 and $20.3 \mathrm{~kg}$, respectively. Although there was no significant mean bias (intercept $=-0.042, P=0.96$ ) or linear bias (slope $=$ $0.0282, P=0.71$; Figure $5 \mathrm{~b}$ ), the relatively poor fit of the regression for the reduced model indicates that this regression equation to estimate rumen liquid volume is not sufficiently accurate for use in research (Figure 5a and $b)$.
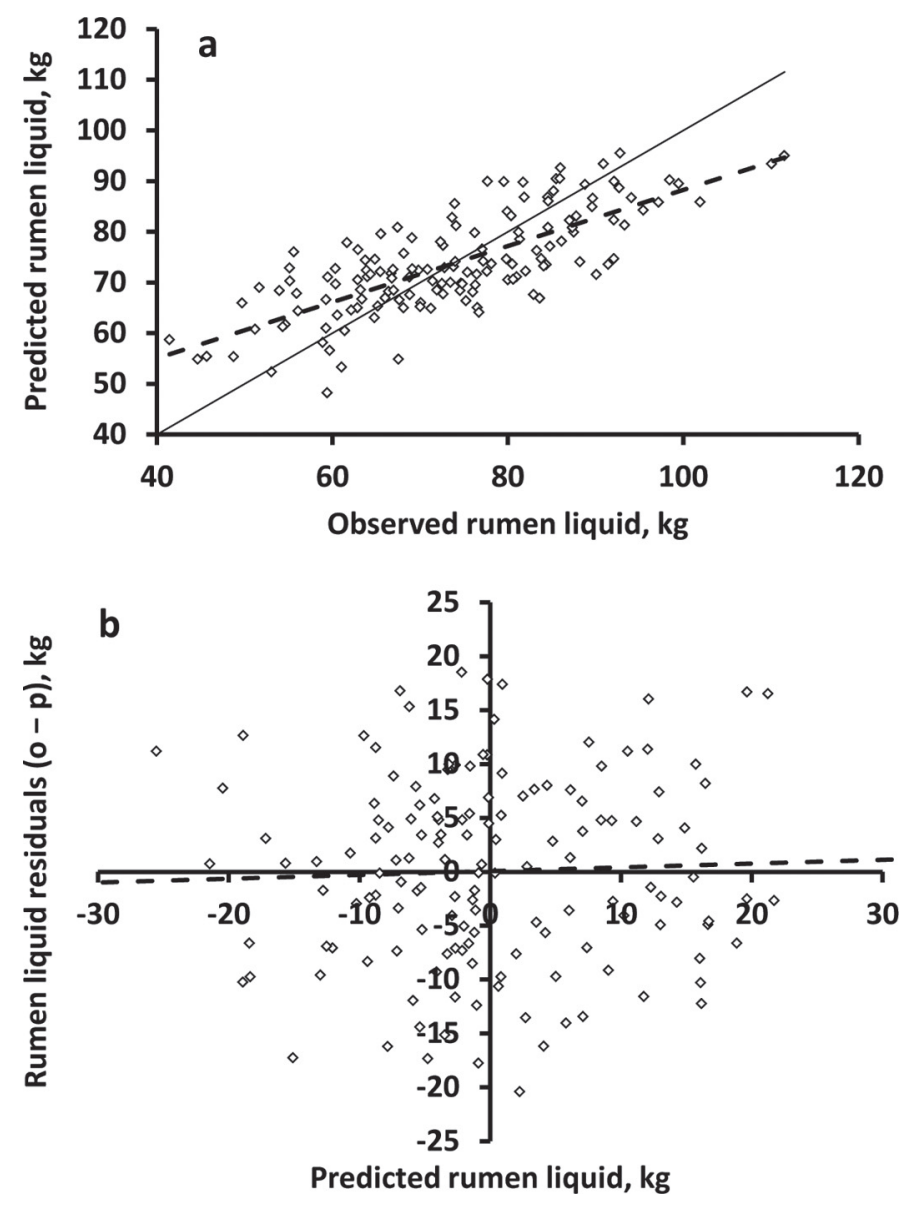

Figure 5. Rumen liquid amounts predicted from regression analyses across studies. (a) Plot of predicted versus observed values: $\mathrm{y}=$ $0.5495 \mathrm{x}+33.3, \mathrm{R}^{2}=0.56$. (b) Plot of residuals (observed - predicted) versus predicted values for rumen liquid amount minus the mean of the predicted values. Dashed lines represent regression lines through the data. 
Moles of ruminal VFA is one of the measures useful for evaluation of rumen function. Although moles of ruminal VFA is calculated from rumen liquid amount, we attempted to predict it separately from rumen liquid. Across all studies, ruminal VFAmol measured $2 \mathrm{~h}$ postfeeding averaged $10.0 \mathrm{~mol}(\mathrm{SD}=3.2$, minimum: 3.5, maximum: 21.0, range: 17.5 ). As was the case for rumen liquid amount, the regression equations for VFA moles also differed among studies as to which variables were significant, although the concentration of $\mathrm{Mg}$ soluble in rumen fluid was significant for all studies (Table 5). The $\mathrm{R}^{2}$ for individual study equations for VFA moles averaged 0.84 , which was higher than that achieved for rumen liquid amount. The mixed model regression analysis for VFA moles gave the following:

Initial equation:

$$
\begin{gathered}
-10.0563+0.07447 \mathrm{DMI}(\mathrm{kg})+0.03496 \text { milk }(\mathrm{kg}) \\
+0.01195 \mathrm{BW}(\mathrm{kg})+0.09795 \mathrm{VFA}(\mathrm{m} M) \\
-0.00178 \mathrm{Na}(\mathrm{mg} / \mathrm{kg})-0.00076 \mathrm{~K}(\mathrm{mg} / \mathrm{kg}) \\
+0.02163 \mathrm{~S}(\mathrm{mg} / \mathrm{kg})-0.185 \mathrm{~B}(\mathrm{mg} / \mathrm{kg})
\end{gathered}
$$

square root of covariance parameter estimates:

$$
\text { study }=0.45, \text { residual }=1.34 ; \mathrm{BIC}=570.2 \text {. }
$$

Reduced equation:

$$
\begin{gathered}
-11.3621+0.07634 \mathrm{DMI}(\mathrm{kg})+0.04747 \text { milk }(\mathrm{kg}) \\
+0.01166 \mathrm{BW}(\mathrm{kg})+0.09729 \mathrm{VFA}(\mathrm{m} M) \\
-0.00127 \mathrm{Na}(\mathrm{mg} / \mathrm{kg})
\end{gathered}
$$

square root of covariance parameter estimates:

$$
\text { study }=0.44 \text {, residual }=1.36 ; \mathrm{BIC}=553.0 .
$$

Compared with the rumen liquid amount regression results, there was less variation related to study or individual measurements, which is also apparent in the graph of predicted versus observed values for the reduced equation (Figure 6a). Based on evaluation of residuals plotted against predicted values, there was no significant mean bias (intercept $=0.0087, P=0.94$ ) or linear bias (slope $=0.0287, P=0.49$; Figure $6 \mathrm{~b}$ ).

The agreement between the VFA mole predictions and actual values was good, but the variability is such that it may not be a sufficiently accurate replacement for determinations of ruminal liquid volume in research. The mean and maximum residuals were 1.1 and 3.5 mol, respectively. It is unknown whether the residuals reflect a deficiency in the regression equation per se, or if such unaccounted-for variability is also inherent in the in vivo values and in methods used to obtain the raw data. We were unable to find information on the method-related variability of liquid determinations obtained through manual rumen emptying, or day-today variability in liquid volumes of animals maintained on the same diet that would affect calculations of VFA moles.

Other methods for determining rumen liquid volume such as use of water-soluble markers have been suggested as accurate given multiple time per day feeding of animals, adequate equilibration of the marker, and accounting for liquid and marker removed during sampling (Teeter and Owens, 1983). In lactating cows fed once daily, use of polyethylene glycol overestimated the manually determined ruminal liquid volume (Stokes et al., 1985). If liquid markers do not equilibrate with liquid within microbes, as much as $20 \%$ of rumen liquid
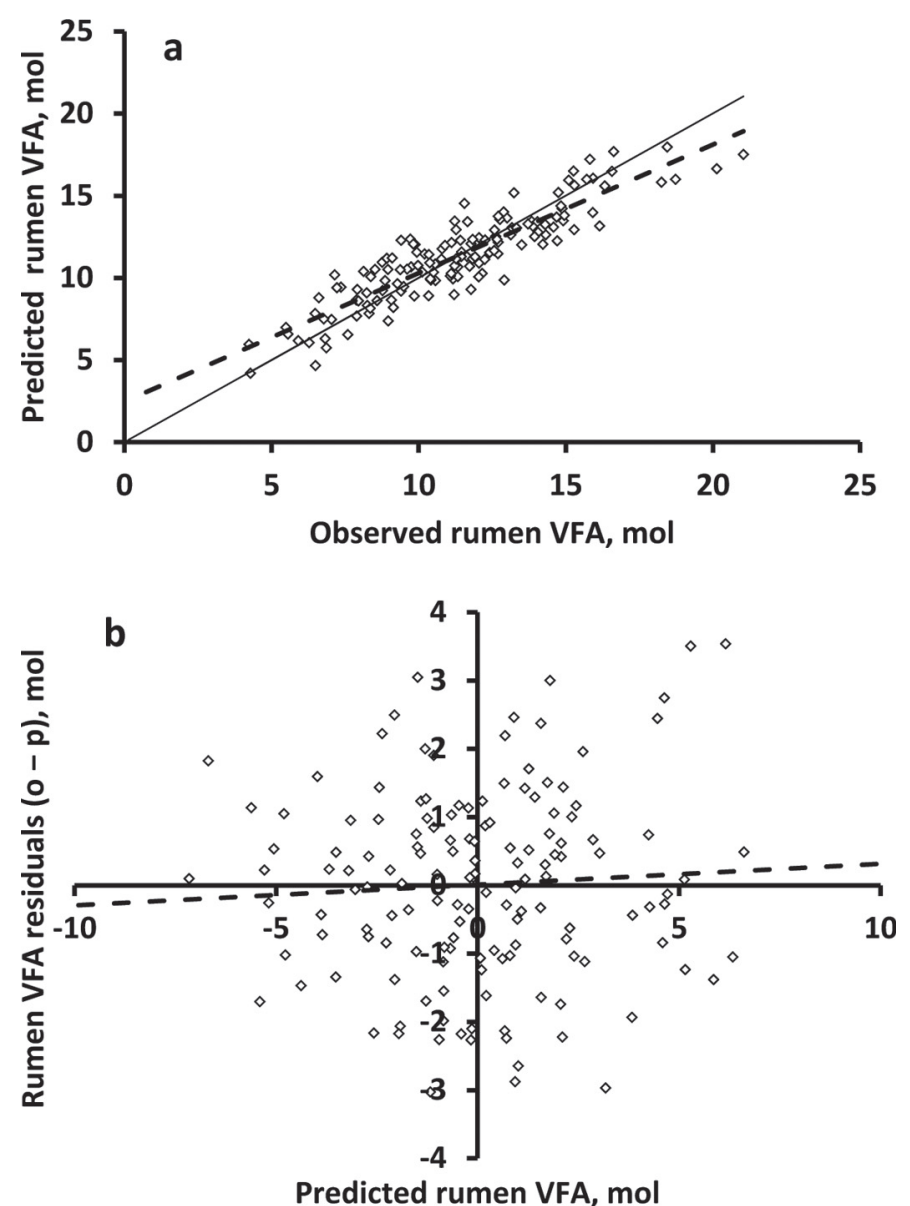

Figure 6. Rumen VFA moles predicted from regression analyses across studies. (a) Plot of predicted versus observed values: $\mathrm{y}=$ $0.7850 \mathrm{x}+2.44, \mathrm{R}^{2}=0.81$. (b) Plot of residuals (observed - predicted) versus predicted values for rumen VFA moles minus the mean of the predicted values. Dashed lines represent regression lines through the data. 
content would not be accounted for (Van Soest, 1994). Ruminal bacteria contain VFA (Russell, 1992) so it does not seem that microbe-associated liquid should be excluded. Additionally, changes in rumen liquid volume during the day that are related to feed ingestion, liquid passage, and absorption from or entry into the rumen (per os or transepithelial) may compromise the determination of rumen volume as the intercept of a regression line through ruminal marker concentrations sampled over time. Linearity of the marker regression curves and estimates of rumen liquid content were changed by the time at which markers were dosed relative to feeding (Stokes et al., 1985). In practice on commercial farms and in most research studies, the rumen does not function in steady state. If we wish to predict rumen function as it reflects the more common reality, methods need to be devised that measure the temporal flux in ruminal digesta.

It would be useful to understand the reasons for entry of factors into the VFA pool size model rather than trusting their inclusion on an empirical basis. Most obviously, inclusion of [VFA] relates directly to the VFA pool size $\times$ liquid amount, and it has been associated with changes in VFA absorption from the rumen (López et al., 2003). Body weight could indirectly describe the potential size of the rumen. Factors that may alter rumen volume as a proportion of BW (e.g., body fat content, pregnancy) could be investigated as modifiers to the relationship of BW with VFAmol. Milk production and DMI may relate to the intake of fermentable substrate. With increasing intake and production, it is also likely that the digestibility of the diet and potential to produce VFA also increase by virtue of changing diet composition to support production. It is unclear what relationship ruminal $\mathrm{Na}$ concentration has to VFAmol. Sodium enters the rumen via saliva and feed and may be absorbed from the rumen (Warner and Stacy, 1972). Although significant in the individual studies, $\mathrm{Mg}$ concentration did not achieve inclusion in the across-studies model. Magnesium solubility increases as $\mathrm{pH}$ becomes more acidic (NRC, 2001), which could occur as a function of the ruminal concentrations of VFA change.

\section{CONCLUSIONS}

The concentrations of VFA in the rumen are not appropriate for use as indicators of the progress of ruminal fermentation or microbial product formation because of the great variability in rumen digesta liquid amounts. The variation in liquid amounts voids the essential requirement that response variables be on equivalent bases to compare them and make statistical inferences. The equivalence of rumen liquid amounts and other nontreatment factors that may affect interpretation of ruminal concentrations should not be assumed. Ruminal pool sizes or molar percentages of VFA may have greater utility for evaluation of treatments because neither is sensitive to ruminal liquid amount. However, measures of pool size that do not consider factors such as absorption and passage from the rumen also do not fully describe fermentation product formation. Predictions of ruminal liquid volume and VFA pool size based on animal measures and ruminal analyte concentrations still had too much variability to serve as replacements for rumen evacuation and direct measurement of ruminal liquid amount. Past conclusions drawn from ruminal concentration data regarding rumen function or treatment effects will need to be revisited with a more accurate method of evaluation.

\section{ACKNOWLEDGMENTS}

We thank J. W. Pitas of USDA-Agricultural Research Service, US Dairy Forage Research Center (Madison, WI) for analytical assistance, and C. Henson of USDAAgricultural Research Service, Cereal Crops Research (Madison, WI) for use of analytical equipment.

\section{REFERENCES}

AOAC International. 1998. Official Methods of Analysis. 16th ed. AOAC Int., Gaithersburg, MD.

Dijkstra, J., H. Boer, J. Van-Bruchem, M. Bruining, and S. Tamminga. 1993. Absorption of volatile fatty acids from the rumen of lactating dairy cows as influenced by volatile fatty acid concentration, $\mathrm{pH}$ and rumen liquid volume. Br. J. Nutr. 69:385-396.

Dobson, A. 1984. Blood flow and absorption from the rumen. Q. J. Exp. Physiol. 69:599-606.

Erwin, E. S., G. J. Marco, and E. M. Emery. 1961. Volatile fatty acid analysis of blood and rumen fluid by gas chromatography. J. Dairy Sci. 44:1768-1774.

Gasa, J., K. Holtenius, J. D. Sutton, M. S. Dhanoa, and J. D. Napper. 1991. Rumen fill and digesta kinetics in lactating Friesian cows given two levels of concentrates with two types of grass silage ad lib. Br. J. Nutr. 66:381-398.

Girard, C. L., C. Benchaar, J. Chiquette, and A. Desrochers. 2009 Net flux of nutrients across the rumen wall of lactating dairy cows as influenced by dietary supplements of folic acid. J. Dairy Sci. 92:6116-6122.

Hall, M. B., C. C. Larson, and C. J. Wilcox. 2010. Carbohydrate source and protein degradability alter lactation, ruminal, and blood measures. J. Dairy Sci. 93:311-322.

Hall, M. B. 2013. Dietary starch source and protein degradability in diets containing sucrose: Effects on ruminal measures and proposed mechanism for degradable protein effects. J. Dairy Sci. 96:7093-7109.

Leng, R. A., and D. J. Brett. 1966. Simultaneous measurements of the rates of production of acetic, propionic and butyric acids in the rumen of sheep on different diets and the correlation between production rates and concentrations of these acids in the rumen. Br. J. Nutr. 20:541-552.

Littell, R. C., G. A. Milliken, W. W. Stroup, R. D. Wolfinger, and O. Schabenberger. 2006. SAS for mixed models, 2nd ed. SAS Institute Inc., Cary, NC.

López, S., F. D. D. Hovell, J. Dijkstra, and J. France. 2003. Effects of volatile fatty acid supply on their absorption and on water kinetics 
in the rumen of sheep sustained by intragastric infusions. J. Anim. Sci. 81:2609-2616.

Merck Veterinary Manual. 1991. 7th ed. C. M. Fraser, ed. Merck \& Co. Inc. Rahway, NJ, p. 1368.

NRC. 2001. Nutrient Requirements of Dairy Cattle. 7th rev. ed. National Academy Press, Washington, DC.

Oba, M., and M. S. Allen. 2003. Effects of corn grain conservation method on feeding behavior and productivity of lactating dairy cows at two dietary starch concentrations. J. Dairy Sci. 86:174183.

Phillipson, A. T. 1942. The fluctuation of $\mathrm{pH}$ and organic acids in the rumen of the sheep. J. Exp. Biol. 19:186-198.

Russell, J. B. 1992. Another explanation for the toxicity of fermentation acids at low $\mathrm{pH}$ : anion accumulation versus uncoupling. J. Appl. Bacteriol. 73:363-370.

SAS Institute. 2013. The SAS System for Windows. Version 9.3. SAS Institute Inc., Cary, NC.

St-Pierre, N. R. 2001. Integrating quantitative findings from multiple studies using mixed model methodology. J. Dairy Sci. 84:741-755.

St-Pierre, N. R. 2003. Reassessment of biases in predicted nitrogen flows to the duodenum by NRC 2001. J. Dairy Sci. 86:344-350.

Stokes, M. R., L. S. Bull, and W. A. Halteman. 1985. Rumen liquid dilution rate in dairy cows fed once daily: Effects of diet and sodium bicarbonate supplementation. J. Dairy Sci. 68:1171-1180.
Sutton, J. D., M. S. Dhanoa, S. V. Morant, J. France, D. J. Napper, and E. Schuller. 2003. Rates of production of acetate, propionate, and butyrate in the rumen of lactating dairy cows given normal and low-roughage diets. J. Dairy Sci. 86:3620-3633.

Tabaru, H., K. Ikeda, E. Kadota, Y. Murakami, H. Yamada, N. Sasaki, and A. Takeuchi. 1990. Effects of osmolality on water, electrolytes and VFAs absorption from the isolated ruminoreticulum in the cow. Nihon Juigaku Zasshi 52:91-96.

Teeter, R. G., and F. N. Owens. 1983. Characteristics of water soluble markers for measuring rumen liquid volume and dilution rate. J. Anim. Sci. 56:717-728.

Van Soest, P. J. 1994. Nutritional Ecology of the Ruminant. 2nd ed. Cornell University Press, Ithaca, NY, p. 249.

Warner, A. C. I., and B. D. Stacy. 1965. Solutes in the rumen of sheep. Q. J. Exp. Physiol. 50:169-184.

Warner, A. C. I., and B. D. Stacy. 1972. Water, sodium and potassium movements across the rumen wall of sheep. Q. J. Exp. Physiol. 57:103-119.

Weimer, P. J., Y. Shi, and C. L. Odt. 1991. A segmented gas/liquid delivery system for continuous culture of microorganisms on solid substrates, and its use for growth of Ruminococcus flavefaciens on cellulose. Appl. Microbiol. Biotechnol. 36:178-183. 